Aim of the study: The aim of the work was to determine the influence of tyrphostin AG1296, an inhibitor of plateletderived growth factor receptor (PDGFR) tyrosine kinase, on autocrine growth of rhabdomyosarcoma (RMS) cells.

Materials and methods: RMS cells were cultured in serum-free DMEM/F12 medium. Modified crystal violet (CV) and MTT methods were used to determine the RMS cells' proliferation and viability. Influence of the investigated inhibitor on cell apoptosis or necrosis was determined by differential staining with Hoechst No. 33258 and propidium iodide. Results: The AG1296 inhibitor affects RMS cell proliferation in a dose-dependent way at the concentration range 1-100 $\mu \mathrm{M}$. At concentrations above $25 \mu \mathrm{M}$ there was $100 \%$ inhibition of growth of these cells and a cytotoxic effect was noticed. $50 \%$ inhibition of RMS cells proliferation ( $\mathrm{I}_{50}$ ) was observed at concentration $6.65 \pm 0.44 \mu \mathrm{M}$ (determined by $\mathrm{CV}$ method) and $7.30 \pm 0.26 \mu \mathrm{M}$ (determined by MTT method). The differential staining method shows that this inhibitor causes a cytotoxic effect.

Conclusion: The results of these experiments indicate that autocrine growth of RMS cells is regulated by at least one autocrine loop, involving platelet-derived growth factor (PDGF) and its re ceptor (PDGFR).

The fact that tyrphostin AG1296 is able to complete inhibition of RMS cell growth in vitro gives a chance for providing a new group of antitumor drugs, which may be more effective than the medicines used so far.

Key words: tyrosine kinase, signal transduction, platelet-derived growth factor receptor, tyrphostin AG1296, RMS cells.

\section{Cytostatic and cytotoxic effects of tyrphostin AG1296 on RMS cells}

\author{
Małgorzata Lasota ${ }^{1,2}$, Andrzej Klein², Walentyna Balwierz
}

1Department of Pediatric Oncology and Hematology, Polish-American Institute of Pediatrics, Faculty of Medicine, Jagiellonian University Medical College, Kraków, Poland ${ }^{2}$ Department of General Biochemistry, Faculty of Biochemistry, Biophysics and Biotechnology, Jagiellonian University, Kraków, Poland

\section{Introduction}

Protein tyrosine kinases (PTK) play a crucial role in the regulation of many cellular processes [1]. Tyrosine kinases are important mediators of the signalling cascade, determining key roles in diverse biological processes such as growth, differentiation, metabolism and apoptosis in response to external and internal stimuli [2]. Their activity is normally tightly controlled and regulated. Perturbation of PTK signalling by mutations and other genetic alterations results in deregulation of kinase activity and malignant transformation [3]. Dysregulation of protein kinases occurs in a variety of diseases including cancer, diabetes, and autoimmune, cardiovascular, inflammatory, and nervous disorders [4].

Though their activity is tightly regulated in normal cells, they may acquire transforming functions due to mutation(s), overexpression and autocrine/paracrine stimulation, leading to malignancy. Normally the level of cellular tyrosine kinase phosphorylation is tightly controlled by the antagonizing effect of tyrosine kinases and tyrosine phosphatases. There are several mechanisms by which tyrosine kinases might acquire transforming functions, but the ultimate result is the constitutive activation of normally controlled pathways leading to the activation of other signalling proteins and secondary messengers, which serves to hamper the regulatory functions in cellular responses such as cell division, growth and cell death. Constitutive activation of tyrosine kinases may occur by several mechanisms. Important mechanisms leading to tyrosine kinase deregulation are mutations, deletions and chromosomal translocation $[2,5]$.

There exists a whole group of oncogenic tyrosine kinases activated by chromosomal translocations, which are included in the fusion tyrosine kinase family due to their structure resemblance. Fusion tyrosine kinases (FTKs) such as $\mathrm{BCR} / \mathrm{ABL}, \mathrm{TEL} / \mathrm{ABL}$, TEL/JAK2, TEL/PDGF $\beta R$, TEL/TRKC(L), and NPM/ALK arise from reciprocal chromosomal translocations and cause acute and chronic leukaemias and non-Hodgkin's lymphoma [6]. FTKs and other oncogenic tyrosine kinases such as $\mathrm{V}$-Src and HER-2/neu activate multiple signalling pathways responsible for protection from apoptosis, induction of growth factor independent proliferation, transformation, and resistance to therapeutic drugs and to $\gamma$-radiation $[6,7]$.

Autocrine-paracrine stimulation serves as an important mechanism for the constitutive activation of tyrosine kinases, especially receptor tyrosine kinases. This activation loop is stimulated when a receptor tyrosine kinase is abnormally expressed or overexpressed in the presence of its associated ligand or when there is overexpression of the ligand in the presence of its cognate receptor. Autocrine/paracrine stimulation plays a role in a variety of human cancers $[2,8]$.

Autocrine loops involving the epidermal growth factor receptor (EGFR), platelet-derived growth factor receptor (PDGFR), or insulin-like growth factor receptor (IGFR) have been described in many cancers [9-14]. Increased expression of EGFR is reported in many human cancers including non-small cell lung can- 
cer, bladder cancer, breast cancer and glioblastoma multiforme [2]. PDGF and its receptor play an important role inlung and prostate lung cancers, renal cell carcinoma, chronic monomyelocytic leukaemia (CMML) and glioblastoma [2, 15]. Co-expression of IGFR and its ligands IGF I and IGF II was reported in the pathogenesis of breast cancer, prostrate cancer and small cell lung cancer [2].

Constitutive oncogenic activation in cancer cells can be blocked by selective tyrosine kinase inhibitors, which is therefore considered a promising approach for innovative genomebased therapeutics. Recent progress in determining the mechanisms by which growth factors control cell proliferation has contributed to the development of treatment strategies that target specific signal transduction pathways to control proliferative disorders. Hence low molecular weight tyrosine phosphorylation inhibitors (tyrphostins) have been proposed to be prospective anti-proliferating agents.

PDGF and its receptors are involved in a variety of diseases: cancers, atherosclerosis, balloon injury induced restenosis, pulmonary fibrosis and more. In all cases enhanced signalling of the receptor is the hallmark. In some cases, such as chronic monomyelocytic leukaemia (CMML), persistent PDGFR signalling is essential for the survival of the cancer cell [15]. These findings induced the research community as well as the pharmaceutical industry to develop agents that block PDGFR signalling (e.g. AG17, AG370, AG1295, STI571, CT52923, SU11248 and more).

These results strongly suggest the potential role of PDGFR inhibitors in RMS cells growth regulation and viability. The aim of the work was to determine the influence of tyrphostin AG1296 (inhibitor of PDGFR tyrosine kinase) on autocrine growth of rhabdomyosarcoma RMS cells.

\section{Materials and methods}

\section{Chemicals and reagents}

Dulbecco's modified minimal essential medium (DMEM), Hoechst No. 33258, propidium iodide and tyrosine kinase inhibitor AG1296 were purchased from Sigma (St. Louis, Mo., USA). Fetal bovine serum (FBS) was obtained from Biowest, South American Origin. Other reagents were provided by POCh (Gliwice, Poland). Stock solutions of the tyrphostin were prepared by dissolving the compounds in dimethylsulfoxide (DMSO) to a final concentration of $10 \mathrm{mM}$ and storing the resultant solutions at $-20^{\circ} \mathrm{C}$. DMEM/F12 $(1: 1)$ medium was used do dilute stock solutions to working concentrations (0.1-100 $\mu \mathrm{M})$.

\section{Cell culture}

RMS cells were obtained from the American Type Culture Collection (ATCC) and cultured in DMEM, supplemented with $100 \mathrm{lU} / \mathrm{ml}$ penicillin and $100 \mathrm{mg} / \mathrm{ml}$ streptomycin in the presence of $10 \%$ fetal bovine serum (FBS). The cells were passaged two times per week using $0.05 \%$ trypsin solution with $0.02 \%$ EDTA in phosphate buffered saline (PBS) without $\mathrm{Ca}^{2+}$ and $\mathrm{Mg}^{2+}$.

\section{Cell proliferation assay}

Target cells were seeded on 96-well plates at concentrations of $8 \times 10^{3}$ cells/well in DMEM, supplemented with $100 \mathrm{lU} / \mathrm{ml}$ penicillin and $100 \mathrm{mg} / \mathrm{ml}$ streptomycin in the pres- ence of 10\% FBS. Following $24 \mathrm{~h}$ of incubation, the culture medium was replaced with serum-free DMEM/F12 (1:1) supplemented with transferrin $(5 \mathrm{mg} / \mathrm{ml})$, sodium selenite $(2 \mathrm{ng} / \mathrm{ml})$ and albumin $(0.5 \mathrm{mg} / \mathrm{ml})$ [DMEM/F12+]. After an additional $24 \mathrm{~h}$ of incubation (Day 0), the medium was replaced with serum-free DMEM/F12+ medium containing tyrosine kinase inhibitor AG1296 (0.1-100 $\mu \mathrm{M})$. The incubation was continued for the next $48 \mathrm{~h}$ at $37^{\circ} \mathrm{C}$ in humidified atmosphere. The modified crystal violet (CV) staining method [16] and the MTT tetrazolium assay (MTT) [17] were used to determine the influence of the tyrphostin on proliferation of target cells. The absorbance was measured using a Tecan (Spectra Fluor Plus) multiscan plate recorder. Ten replicate wells were used for each experiment. The influence of tyrosine kinase inhibitors was expressed as a relative (to the controls) decrease in cell growth determined after $48 \mathrm{~h}$ of incubation with the investigated compounds. The calculated parameter was:

$$
G_{i}=\frac{\bar{A}_{i}-\bar{A}_{O}}{\bar{A}_{C}-\bar{A}_{O}} \cdot 100 \%
$$

where $\mathrm{G} i$ is growth inhibition, and $\mathrm{Ao}, \mathrm{Ac}, \mathrm{Ai}$ are average values of absorbance at $540 \mathrm{~nm}$ (CV) or $570 \mathrm{~nm}$ (MTT) of the control sample at the start of the experiment (Ao), after $48 \mathrm{~h}$ of incubation (Ac), and after $48 \mathrm{~h}$ of incubation with the investigated inhibitors (Ai).

\section{Assessment of cell viability}

The differential staining method (Hoechst 33258/PI) was used in the investigation of the effect of tyrphostin AG1296 on the viability of RMS cells [18]. The cells were seeded on 24-well plates at a density of $3 \times 10^{4}$ per well in $0.8 \mathrm{ml}$ DMEM with $10 \%$ FBS. Following $24 \mathrm{~h}$ of incubation, the culture medium was replaced with serum-free DMEM/F12+ medium. After an additional $24 \mathrm{~h}$ of incubation, the cells were exposed to $10-100 \mu \mathrm{M}$ concentrations of the investigated tyrphostin and $50 \mathrm{nM}$ paclitaxel (Taxol). The experiment was carried out for $48 \mathrm{~h}$ and then Hoechst No. 33258 and propidium iodide were added to the final concentration of $5 \mu \mathrm{g} / \mathrm{ml}$ and $1 \mu \mathrm{g} / \mathrm{ml}$, respectively. After $15 \mathrm{~min}$, the cells were directly examined on plates with a fluorescent Olympus IMT 2 microscope. Two excitation filters were used: one allowing for excitation of both dyes, the other allowing for excitation of only PI. The Image J software was used for image processing (emerging RGB channels, enhancing contrast and sharpening) and the quantitative analysis of the processed pictures (cell counting). It allowed for estimating the fraction of dead cells (PI/DNA signal), viable cells (Hoechst 33258/DNA signal), and apoptotic cells (Hoechst 33258/DNA signal with morphological changes characteristic of last-phase apoptosis). Each experiment was repeated at least six times. Images with the number of cells exceeding approximately 100 were selected for the analysis.

\section{Statistical analysis}

The statistical analysis was performed using the Statistica 6 program. The effects of different tyrphostin concentrations on RMS cell proliferation were analysed using one way ANOVA, followed by Dunnett's test. The Mann Whitney 
$U$ test was used to determine differences in the percentage of alive, apoptotic and necrotic cells in the control sample versus tyrphostin or paclitaxel (Taxol) treated samples. Differences were considered significant at $p<0.05$. The mean \pm SEM of at least ten replicates (CV) or four replicates (differential staining method) were used for statistical comparison.

\section{Results}

Rhabdomyosarcoma cells were exposed for $48 \mathrm{~h}$ to tyrosine kinase inhibitor AG1296 added at the concentration range of $0.1-100 \mu \mathrm{M}$. The effect of the investigated tyrphostin determined by the CV and MTT methods is shown in Fig. 1.

The AG1296 inhibitor affects RMS cell proliferation in a dose-dependent manner at the concentration range 1-100 $\mu \mathrm{M}$. Both methods showed $50 \%$ inhibition of cell growth in the concentration range 5-10 $\mu \mathrm{M}$. Tyrphostin AG1296 caused an effect of growth inhibition (Gi) of RMS cells. The growth of the investigated cells was almost completely inhibited at concentration $25 \mu \mathrm{M}$. Gi reached $93.79 \pm 5.37 \%$ (determined by the CV method) and $88.91 \pm 5.17 \%$ (by MTT method). At concentrations higher than $25 \mu \mathrm{M}$ there was $100 \%$ inhibition of growth of these cells and a cytotoxic effect was observed.

$50 \%$ inhibition of the growth of RMS cells was determined by fitting a sigmoidal model of the dose-dependent effect

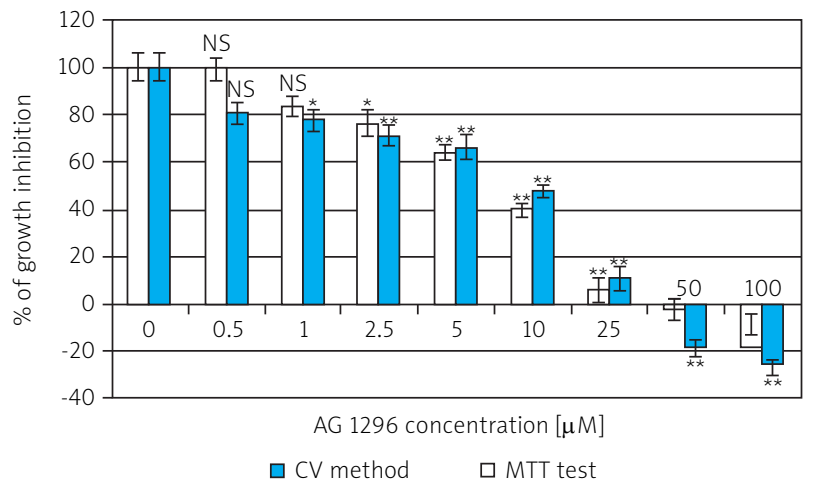

Fig. 1. Growth inhibition of cancer cell line (RMS) by inhibitor AG1296 determined by modified crystal violet staining method and MTT test after $48 \mathrm{~h}$ of incubation in serum-free medium (DMEM/F12)

NS - non-significant $(p>0.05)$ in comparison with control sample (without AG1296); ${ }^{*} 0.01<p<0.05,{ }^{* *} 0.001<p<0.01$ of the investigated tyrphostin (Fig. 2), calculated from the equation:

$$
H[\% K]=\frac{100}{1+10 \log \left(/ C_{50}-C_{\text {inh }}\right) \cdot p}
$$

$\mathrm{IC}_{50}$ coefficient calculated from the growth inhibition curves was $7.76 \pm 0.35 \mu \mathrm{M}$ for AG1296. The results showed a cytostatic activity against RMS cells of the investigated tyrosine kinase inhibitor.

The investigated tyrosine kinase inhibitor was also examined for its cytotoxic potential and the ability to induce tumour cell apoptosis or necrosis. The influence of tyrphostin AG1296 on target cell viability was assessed after double staining with Hoechst 33258 and propidium iodide. Viable cells were dyed on blue, apoptotic on light-blue and necrotic cells on red. The effect of $10 \mu \mathrm{M}$ concentration of tyrphostin AG1296 in comparison with the $50 \mathrm{nM}$ dose of paclitaxel is shown in Fig. 3.

Apoptosis is the predominant form of cell death and occurs under a variety of physiological and pathological conditions. Apoptotic cells were clearly distinguishable by their characteristic morphology (cytoplasmic blebbing, cell shrinkage, nuclear condensation and fragmentation) (Fig. 3). Such morphological alterations were found in all investigated cell cultures; however, in the case of control cultures, they did not exceed $10 \%$ of the total cell population. The results of

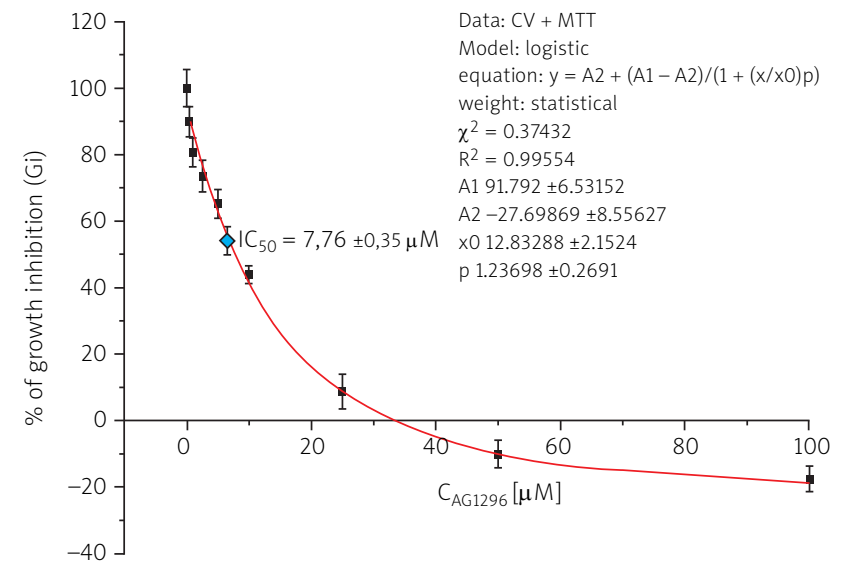

Fig. 2. Dose-dependent effect of tyrphostin AG1296 on the growth of RMS cells after $48 \mathrm{~h}$ of incubation in serum-free DMEM/F12+ medium
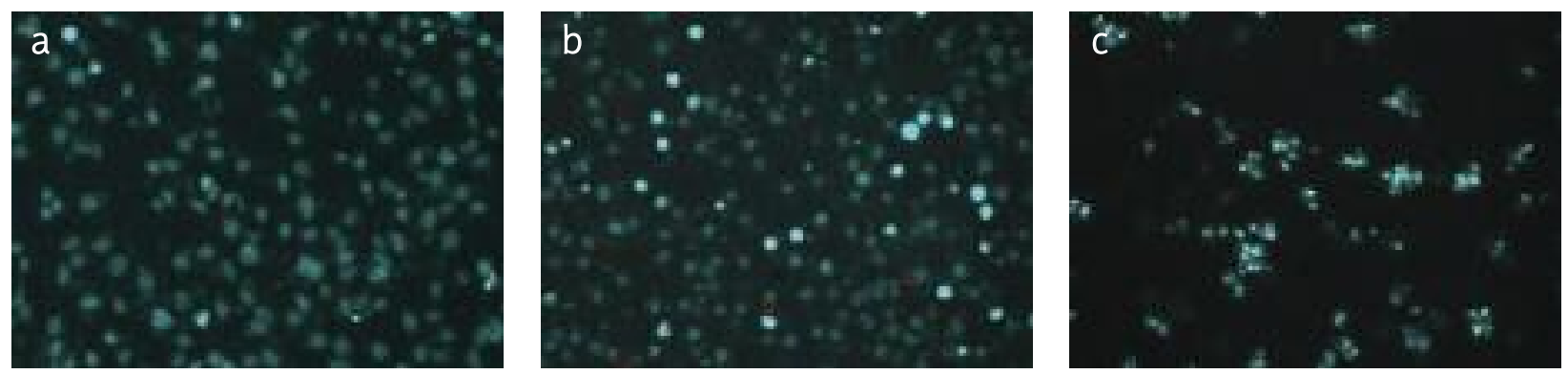

Fig. 3. Typical picture of the cultures of RMS cells after $48 \mathrm{~h}$ of incubation: a) control, b) $10 \mu \mathrm{M}$ AG1296 and c) $50 \mathrm{nM}$ Taxol Dark blue - viable cells; blue (with nuclear fragmentation) - apoptotic cells; red - necrotic cells 


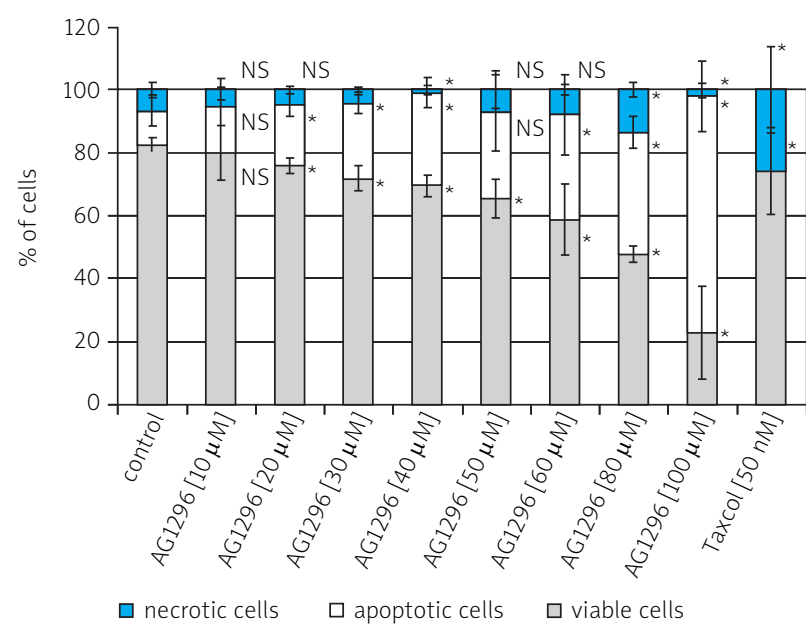

Fig. 4. Effect of tyrphostin AG1296 and Taxol (as the positive control) on the induction of apoptosis in RMS cells, after $48 \mathrm{~h}$ of incubation in DMEM/F12+ medium. The average percentage of viable cells, apoptotic cells and necrotic cells

${ }^{* * *} p<0.001 ;{ }^{* *} 0.001<p<0.01 ;{ }^{*} 0.01<p<0.05 ;$ NS - non-significant

quantitative determination of the number of viable, apoptotic and necrotic cells are presented in Fig. 4.

Quantitative results obtained in the study confirm the microscopic observations. The differential staining method proved that this inhibitor caused a cytotoxic effect. The percentage of apoptotic cells was increased in a dose-dependent manner by treatment with tyrphostin AG1296. Between the control and different concentrations of tested inhibitor the amount of viable cells is successively dropping (four times at the highest concentration of tyrphostin). With increasing concentration of AG1296, the percentage of apoptotic cells increases (from 11.1\% for the control to $75.3 \%$ for concentration of $100 \mu \mathrm{M}$ ). The obtained results are statistically significant. Only for $50 \mu \mathrm{M}$ concentration of tyrphostin are the amounts of apoptotic cells for the inhibitor and the control not significantly different. This is probably due to the large dispersion of obtained results. The results presented clearly indicate the cytotoxic effect of the action of the tested PDGFR inhibitor. Prolonging the incubation time to $72 \mathrm{~h}$ resulted in a dramatic decrease of viability of cells to about $40 \%$ (results not shown).

\section{Discussion}

Rhabdomyosarcoma (RMS) is the most frequent childhood cancer originating from skeletal muscle, and patient survival is poor in the case of metastatic disease. New targeted therapeutics are critically needed [19]. Over the past two decades, research into the molecular mechanisms of RMS has identified key genes and signalling pathways involved in disease pathogenesis. Several members of the receptor tyrosine kinase (RTK) family of cell surface receptors have been characterized as druggable targets for RMS. Through small molecule inhibitors, ligand-neutralizing agents, and monoclonal receptor-blocking antibodies, RTK activity can be manipulated to block oncogenic properties associated with RMS [20].

The role of tyrosine kinases in cancer molecular pathogenesis is immense and recently kinases have come into vogue as potential anticancer drug targets, as a result of a couple of anticancer drugs that are on the market. The complexity and the number of tyrosine kinases have greatly increased with the sequencing effort of the Human Genome Project, thus providing more opportunities for drug discovery. Recent understanding of the molecular pathophysiology of cancer has highlighted that many tyrosine kinases are found upstream or downstream of epidemiologically relevant oncogenes or tumour suppressors, in particular the receptor tyrosine kinases [2].

Several types of PDGF antagonists have been described, including antibodies or DNA aptamers against ligands or the extracellular part of the receptors, as well as low molecular weight receptor kinase inhibitors (e.g. imatinib, sunitinib and sorafenib) [21-27]. The latter also inhibited the growth of RMS cells $\left(I C_{50}=5 \mu M\right)$ [28]. Imatinib represents a kinase inhibitor for which there is already some clinical experience [21, 29]. Another PDGF receptor antagonist that, despite having a broad specificity, shows a tolerable toxicity profile and promising results from phase I clinical trials is SU11248 [21]. The mechanism of action of AG1296, a potent and specific inhibitor of the platelet-derived growth factor (PDGF) receptor tyrosine kinase, has been investigated [30-32].

We have determined whether blockade of PDGFR signalling pathways inhibits autocrine growth and viability of RMS cells in vitro. In RMS cells, AG1296 inhibited proliferation in a dosedependent manner with an $I C_{50}$ value of $7.76 \pm 0.35 \mu \mathrm{M}$. Our results indicate that each of the investigated tyrphostins at concentrations $>25 \mu \mathrm{M}$ is able to completely inhibit RMS autocrine cell growth. The obtained results were very similar, regardless of the method of growth evaluation which was applied (CV, MTT). At concentrations higher than $40 \mu \mathrm{M}$, the amount of cells dropped below the initial density, which indicated the cytotoxic effect.

The differential staining method showed that the investigated tyrphostin, used at concentration $>10 \mu \mathrm{M}$, had direct cytotoxicity on the RMS cell line. After the 48-hour incubation the percentage of viable cells decreased significantly with the increase of tyrphostin concentration and equalled 75.9\% (20 $\mu$ M concentration), 69.4\% (40 $\mu$ M concentration), $58.7 \%$ ( $80 \mu \mathrm{M}$ concentration) and $22.6 \%$ (100 $\mu \mathrm{M}$ concentration). It turned out that the kinase inhibitor PDGFR stimulates mainly the apoptotic process of the investigated cells. The amount of apoptotic cells increased from $18.5 \%$ for the $20 \mu \mathrm{M}$ concentration of tyrphostin AG1296 to $75.5 \%$ for the $100 \mu \mathrm{M}$ concentration of tyrphostin AG1296. With the incubation time prolonged to $72 \mathrm{~h}$ there was still observed a decrease of the number of viable cells to $12.9 \%$ and an increase of the amount of necrotic cells up to $25 \%$.

The results of these experiments indicate that autocrine growth of RMS cells is regulated by at least one autocrine loop, involving PDGF and its receptor (PDGFR). The fact that tyrphostin AG1296 is able to complete inhibition of RMS cell growth in vitro gives a chance for providing a new group of antitumor drugs, which may be more effective than the medicines used so far. 


\section{References}

1. Kemp BE, Pearson RB. Protein kinase recognition sequence motifs. Trends Biochem Sci 1990; 15: 342-6.

2. Manash PK, Anup MK. Tyrosine kinase - Role and significance in Cancer. Int J Med Sci 2004; 1: 101-15.

3. Blume-Jensen P, Hunter T. Oncogenic kinase signalling. Nature 2001; 411: 355-65.

4. Roskoski Jr R. The ErbB/HER receptor protein-tyrosine kinases and cancer. Biochem Biophys Res Commun 2004; 319: 1-11.

5. Bertram JS. The molecular biology of cancer. Mol Aspects Med 2000; 21: $167-223$.

6. Slupianek A, Hoser G, Majsterek I, Bronisz A, Malecki M, Blasiak J, Fishel R, Skorski T. Fusion tyrosine kinases induce drug resistance by stimulation of homology-dependent recombination repair, prolongation of $\mathrm{G} 2 / \mathrm{M}$ phase, and protection from apoptosis. Mol Cell Biol 2002; 22: 4189

7. Hochhaus A, Kreil S, Corbin A, et al. Roots of clinical resistance to STI-571 cancer therapy. Science 2001; 293: 2163.

8. Kulik G, Klippel A, Weber MJ. Antiapoptotic signalling by the insulinlike growth factor I receptor, phosphatidylinositol 3-kinase, and Akt. Mol Cell Biol 1997; 17: 1595-606.

9. Berlanga-Acosta J, Gavilondo-Cowley J, del Barco-Herrera D, et al. Epidermal growth factor (EGF) and platelet-derived growth facto (PDGF) as tissue healing agents: clarifying concerns about their possible role in malignant transformation and tumor progression. J Carcinogene Mutagene 2011; 1: 115.

10. Rojas A, Liu G, Coleman I, et al. IL-6 promotes prostate tumorigen esis and progression through autocrine cross-activation of IGF-IR Oncogene 2011; 20: 2345-55.

11. Martins AS, Olmos D, Missiaglia E, Shipley J. Targeting the insulinlike growth factor pathway in rhabdomyosarcomas: rationale and future perspectives. Sarcoma 2011; 2011: 209736.

12. Ciaraldi TP, Sasaoka T. Review on the in vitro interaction of insulin glargine with the insulin/insulin-like growth factor system: potential implications for metabolic and mitogenic activities. Horm Metab Res 2011; 43: 1-10.

13. Östman A. PDGF receptors-mediators of autocrine tumor growth and regulators of tumor vasculature and stroma. Cytokine Growth Factor Rev 2004; 15: 275-86.

14. Ranson M, Hammond LA, Ferry D, et al. ZD1839, a selective oral epidermal growth factor receptor-tyrosine kinase inhibitor, is well tolerated and active in patients with solid, malignant tumors: results of a phase I trial. J Clin Oncol 2002; 20: 2240-50.

15. Levitzki A. PDGF receptor kinase inhibitors for the treatment of PDGF driven diseases. Cytokine Growth Factor Rev 2004; 15: 229-35.

16. Gillies RJ, Didier N, Denton M. Determination of cell number in monolayer cultures. Anal Biochem 1986; 159: 109-13.

17. Mosmann T. Rapid colorimetric assay for cellular growth and survival: application to proliferation and cytotoxicity assays. J Immunol Methods 1983; 65: 55-63.

18. Darzynkiewicz Z, Li X, Gong J. Assays of cell viability: discrimination of cells dying by apoptosis. Methods Cell Biol 1994; 41: 15-38.

19. Barti-Juhasz H, Mihalik R, Nagy K, Grisendi G, Dominici M, Petak I. Bone marrow derived mesenchymal stem/stromal cells transduced with full length human TRAIL repress the growth of rhabdomyosarcoma cells in vitro. Haematologica 2011; 96: e21-2.

20. Crose LE, Linardic CM. Receptor tyrosine kinases as therapeutic targets in rhabdomyosarcoma. Sarcoma 2011; 2011: 756982.

21. Pietras K, Sjöblom T, Rubin K, Heldin CH, Ostman A. PDGF receptors as cancer drug targets. Cancer Cell 2003; 3: 439-43.

22. Yoshitani K, Honoki K, Morishita T, Kido A, Miyauchi Y, Mii Y, Takakura Y. Growth inhibition of rat osteosarcoma and malignant fibrous histiocytoma cells by tyrosine kinase inhibitor STI571. In Vivo 2003; 17: 255-8.

23. McGary EC, Weber K, Mills L, Doucet M, Lewis V, Lev DC, Fidler IJ, BarEli M. Inhibition of platet-derived growth factor mediated proliferation of osteosarcoma cells by the novel tyrosine kinase inhibitor STI5711. Clin Cancer Res 2002; 8: 3584-91.

24. Slater O, Shipley J. Clinical relevance of molecular genetics to paediatric sarcomas. J Clin Pathol 2007; 60: 1187-94.

25. Armistead PM, Salganick J, Roh JS, et al. Expression of receptor tyrosine kinases and apoptotic molecules in rhabdomyosarcoma: correlation with overall survival in 105 patients. Cancer 2007; 110: 2293-303.

26. Kreuter M, Paulussen M, Boeckeler J, et al. Clinical significance of Vascular Endothelial Growth Factor-A expression in Ewing's sarcoma. Eur J Cancer 2006; 42: 1904-11.

27. Gee MF, Tsuchida R, Eichler-Jonsson C, Das B, Baruchel S, Malkin D. Vascular endothelial growth factor acts in an autocrine manner in rhabdomyosarcoma cell lines and can be inhibited with all-transretinoic acid. Oncogene 2005; 24: 8025-37.

28. Maruwge W, D’Arcy P, Folin A, et al. Sorafenib inhibits tumor growth and vascularization of rhabdomyosarcoma cells by blocking IGF-1Rmediated signaling. Onco Targets Ther 2008; 1: 67-78.

29. Capdeville R, Buchdunger E, Zimmermann J, Matter A. Glivec (STI571, imatinib), a rationally developed, targeted anticancer drug. Nat Rev Drug Discov 2002; 1: 493-502.

30. Kovalenko M, Rönnstrand L, Heldin CH, Loubtchenkov M, Gazit A, Levitzki A, Böhmer FD. Phosphorylation site-specific inhibition of platelet-derived growth factor beta-receptor autophosphorylation by the receptor blocking tyrphostin AG1296. Biochemistry 1997; 36: 6260-9.

31. Ahn HY, Hadizadeh KR, Seul C, Yun YP, Vetter H, Sachinidis A. Epigallocathechin-3 gallate selectively inhibits the PDGF-BB-induced intracellular signaling transduction pathway in vascular smooth muscle cells and inhibits transformation of sis-transfected NIH 3T3 fibroblasts and human glioblastoma cells (A172). Mol Biol Cell 1999; 10: 1093-104.

32. Kumar RN, Ha JH, Radhakrishnan R, Dhanasekaran DN. Transactivation of platelet-derived growth factor receptor alpha by the GTPase-deficient activated mutant of Galpha12. Mol Cell Biol 2006; 26: 50-62.

\section{Address for correspondence}

\section{Małgorzata Lasota}

Klinika Onkologii i Hematologii Dziecięcej

Polsko-Amerykański Instytut Pediatrii

ul. Wielicka 265

30-663 Kraków

e-mail: malgorzata.lasota@uj.edu.pl

Submitted: $\quad 3.06 .2011$

Accepted: $\quad 18.01 .2012$ 